\title{
Choice of Restorative Material for Endodontically Treated Teeth in Teaching Institutions of Multan
}

\author{
Mehwish Rafiq ${ }^{1}$ \\ BDS \\ Tahira Parveen ${ }^{2}$ \\ BDS \\ Uzma Abdullah ${ }^{3}$ \\ BDS \\ Jaffar Hussain Bukhari ${ }^{4}$ \\ BDS, M.Phil
}

OBJECTIVE: The purpose of this study was to describe the knowledge, attitude and practice for core build-up and crowning of endodontically treated teeth in teaching institutes of Multan and to assess the association of clinical experience, work place and qualification on these options.

METHODOLOGY: A cross sectional study was conducted using self-applied questionnaire with dentists working in three teaching institutes of Multan from 22nd to 28th October, 2019. The calculated sample size for the total population of 160 was 114 according to Raosoft sample size calculator by keeping the confidence level 95\%. A total of 160 questionnaires were distributed. Recovered questionnaires were 148. Response rate was 92\%. Information about clinical experience, work place and post-graduation qualification was collected. Data regarding preference of core build-up material, crown material, timing of restoration of endodontically treated teeth (ETT), type of post was collected. Data were analyzed by SPSS version 22, frequencies and percentage were obtained. Association between different variables was calculated using Pearson's chi-square test.

RESULTS: Amalgam was preferred as core buildup material on the basis of strength (81\%), immediate restoration of ETT was preferred by private sector participants (30\%) and restoration after one week was preferred by public sector participants (45.9\%). Most of the participants believed core buildup must receive endopost to have better prognosis (60\%). Majority preferred prefabricated endopost (50\%) over custom made post $(33 \%)$. The porcelain fused to metal crown was preferred as the clinical experience of dentist increases $(\mathrm{p}=0.001)$.

CONCLUSION: Within the limitations of the study, it was concluded that amalgam was preferred as core buildup material, prefabricated post was preferred over custom made and PFM was material of choice for crowning.

KEYWORDS: Dental practitioners, endodontically treated tooth, post and core, restoration, survey, core build-up. HOW TO CITE: Rafiq M, Parveen T, Abdullah U, Bukhari JH. Choice of Restorative Material for Endodontically Treated Teeth in Teaching Institutions of Multan . J Pak Dent Assoc 2020;29(3):130-134.

DOI: https://doi.org/10.25301/JPDA.293.130

Received: 26 February 2020, Accepted: 21 May 2020

\section{INTRODUCTION}

$\mathrm{T}$ he endodontic and restorative dentistry is the study of preservation of natural tooth structure. Endodontic treatment is required for grossly carious, fractured or badly broken down vital or non-vital teeth. ${ }^{1}$ The loss of tooth structure in endodontic treatment due to caries or endodontic procedure increases the vulnerability of the tooth to fracture. The longevity of such teeth rely on the amount of tooth loss and the ability of restorative material to replace

1. Demonstrator, Department of Dental Materials, Nishtar Institute of Dentistry Multan. 2. Demonstrator, Department of Oral Biology, Nishtar Institute of Dentistry Multan.

3. Demonstrator, Department of Oral Biology, Nishtar Institute of Dentistry Multan.

4. Assistant Professor, Department of Dental Materials, Nishtar Institute of Dentistry Multan.

Corresponding author: "Dr. Mehwish Rafiq" < mehwishyasir47@gmail.com > the missing tooth structure. ${ }^{2}$ It requires distinctive consideration where there is extensive loss of tooth structure. In addition, the prognosis of endodontically treated tooth (ETT) depends upon multiple criteria such as the amount of remaining tooth structure ${ }^{3}$, type of final restoration, design of the post, and type of core build-up material used. ${ }^{4}$

There is general concept that endodontic treatment failure might be due to restoration failure, therefore selection of restorative material, technique and time of restoration are significant factors. ${ }^{5}$ It is further suggested that appropriate and early permanent restoration after completion of endodontic treatment should be carried out. When temporary filling is followed by permanent restoration to seal the access cavity, there are more chances of leakage and bacterial invasion. ${ }^{6}$ There are more chances of leakage and bacterial 
invasion when temporary filling is followed by permanent restoration to seal the access. Endodontically treated teeth having permanent restoration are more successful as compared to temporary restoration. ${ }^{6-8}$

A core build-up is a restoration that is used to restore the coronal portion of the badly broken down tooth. As core build-up material restores large bulk of missing tooth structure and resists multidirectional chewing forces for many years, it's compressive and tensile strength are important factors for better prognosis of ETT. ${ }^{9}$ To enable the retention of core build-up material, they are usually reinforced by pins, post and bonding system. A dental post is a material placed in the root of a structurally insufficient tooth to provide additional retention and support the coronal restoration. The post should provide this support without increasing the risk of root fracture. ${ }^{10}$

A number of dental materials have been used for core build-up. ${ }^{11}$ They are direct and indirect material namely pin retained restoration and prefabricated post or custom made post and core respectively. ${ }^{12}$ The material used as core build-up includes amalgam, glass ionomer cement, resin modified glass ionomer cement, cermet and composite resin. Composite resin is mostly used to build-up the core of the missing tooth. ${ }^{12}$

For restoration of ETT different procedures have been recommended. These treatment procedures include the use of post and core, partial or full crowns, and direct resin composite or amalgam fillings. The available post and core systems are custom made and pre-fabricated. When the coronal tooth structure is insufficient to retain a core buildup then posts are recommended.

The endodontically treated tooth can be used as abutment but there were chances of fracture of those ETT that had post and were terminal abutments. ${ }^{13}$ The clinical success of ETT is significantly increased with coronal coverage. ${ }^{14}$ It has been found that ETT without coronal coverage failed six times greater than crowned teeth. ${ }^{15}$ The prognosis of posterior ETT is considerably increased with crowning, however in anterior ETT crowning has not much significance. ${ }^{15}$

To assess and understand treatment approaches for ETT restorations, surveys are important tools. ${ }^{12}$ Several survey based studies have been published regarding restoration of ETT. However, the preference and strategies of dental practitioners in teaching institutes of Multan need to be investigated. The purpose of this study was to analyze the preference, techniques.

\section{METHODOLOGY}

A cross-sectional study was performed from 22nd to 28th October, 2019 in three teaching institutes of Multan; Nishter institute of dentistry (NID), Bakhtawar Amin medical and dental college (BAMDC) and Multan medical and dental college (MMDC). Non-probability convenience sampling was done in this survey. The total population of registered dentists working in above mentioned institutions was 160. Questionnaires were distributed among them. The number of recovered questionnaires was 148 bringing the response rate to $92.5 \%$. The calculated sample size for the total population of 160 was 114 according to Raosoft sample size calculator by keeping the confidence level $95 \%$.

Data were collected non-specifically using a fifteenquestion survey questionnaire. Questionnaire comprised of questions regarding clinician's demographics (designation, area of interest/expertise and clinical experience), endodontic procedure preference, choice of material for core build-up, type of post, preference of crowning and type of crown material preferred. The collected data were analyzed and interpreted using SPSS version 22. The association between designation of the clinicians and rest of the variables mentioned above was analyzed using Pearson's chi-square test. A significance level of $\mathrm{p} \leq 0.05$ and confidence level of $95 \%$ was used.

\section{RESULTS}

From the population of dentists (160) working in the targeted institutions, 148 participated in the study $(\mathrm{n}=140)$. The data missed was $7.5 \%$ due to no return of the questionnaire and absence of the participants from the workplace. Among the respondents having experience greater than 10 years were $26 \%$, those having less than 10 years were $25 \%$ and less than 5 years were $97 \%$. The working place of the participants was $54.7 \%$ at public place, $30.4 \%$ at private and $14.9 \%$ were at both places. Postgraduate participants were $31.1 \%$ while $68.9 \%$ were graduates. The frequencies and percentages of studied variables are shown in Table 1.

Table 1: The frequencies and percentages of studied variables

\begin{tabular}{|ccc|}
\hline Variables & Frequency $=\mathrm{n}$ & Percentage \\
\hline 1. Type of tooth restored with core build materials. & 15 & 10.1 \\
Vital & 45 & 30.4 \\
Non-vital & 49 & 33.1 \\
Both a \& b & 39 & 26.4 \\
Badly broken & 120 & \\
Strength & 13 & 81.1 \\
Aesthetics & 6 & 4.8 \\
Cost effectiveness & 9 & 6.1 \\
\hline 2. Choice of core build-up material on the basis of & & \\
Ease of availability and handling & 45 & 30.4 \\
Immediately after obturation & 25 & 16.9 \\
24 hours after obturation & 68 & 45.9 \\
One week after obturation & 10 & 6.8 \\
Several weeks after obturation & & \\
\hline
\end{tabular}




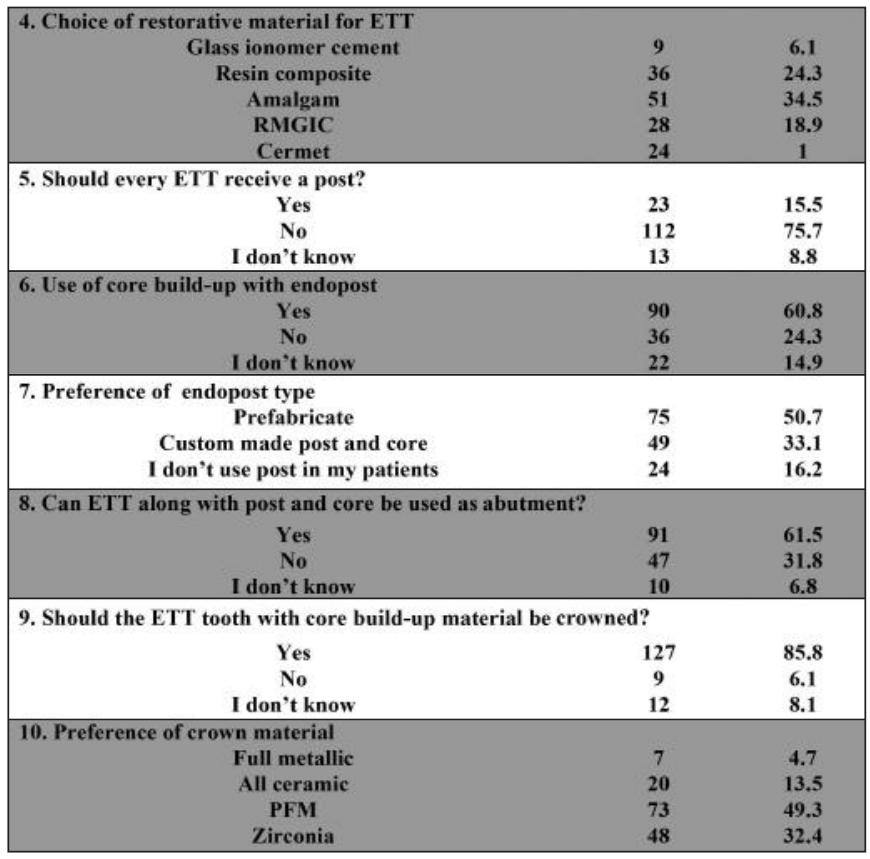

Table 2: Association of experience with crown material and buildup time with place of working

\begin{tabular}{|c|c|c|c|c|}
\hline \multirow{2}{*}{ Crown material } & \multicolumn{3}{|c|}{ Experience (years) } & \multirow{2}{*}{ P value } \\
\cline { 2 - 4 } & $<5$ & $\mathbf{6 - 1 0}$ & $>10$ & \\
\hline FMC* & 3 & 4 & 0 & \multirow{2}{*}{0.001} \\
\hline All ceramic & 12 & 7 & 1 & \\
\hline PFM** & 42 & 18 & 13 & \\
\hline Zirconia & 37 & 4 & 3 & \\
\hline Buildup time & \multicolumn{3}{|c|}{ Place } & \multirow{2}{*}{0.002} \\
\cline { 2 - 4 } & Private & Public & Both & \\
\hline Immediately & 23 & 13 & 9 & \multirow{2}{*}{1} \\
\hline 24 hours & 6 & 18 & 1 & \\
\hline One week & 15 & 43 & 10 & \\
\hline Several weeks & 1 & 7 & 2 & \\
\hline
\end{tabular}

$* \mathrm{FMC}=$ full metallic crown $* * \mathrm{PFM}=$ porcelain fused to metal

Table 3: Association of post-graduation with endo-post type and crowning ETT

\begin{tabular}{|c|c|c|c|}
\hline \multirow{2}{*}{ Endo-post type } & \multicolumn{2}{|c|}{ Post-graduation } & \multirow{2}{*}{ P value } \\
\cline { 2 - 3 } & Yes & No & \\
\hline Prefabricated & 31 & 44 & \multirow{2}{*}{0.003} \\
\hline Custom made & 14 & 35 & \\
\hline I don't know & 1 & 23 & \\
\hline $\begin{array}{c}\text { Crowning of } \\
\text { ETT }\end{array}$ & \multicolumn{2}{|c}{} & \\
\hline Yes & 44 & 83 & \\
\hline No & 2 & 7 & 0.039 \\
\hline I don't know & 0 & 12 & \\
\hline
\end{tabular}

There was a statistically significant association between the restoration times of ETT and work place, given in the Table 2. The participant who were in public place opted "restoration after one week" significantly more than those working at private places $(\mathrm{p}=0.002)$. Majority of participants $(62 \%)$ had chosen endopost in ETT and prefabricated post were preferred over custom made post $(p=0.003)$ given in the table 3. Most of the participants $(85.6 \%)$ preferred such tooth should be crowned $(\mathrm{p}=0.39)$ shown in table 3 . The respondents who had more than ten years of experience $(76 \%)$ preferred PFM crown $(\mathrm{p}=0.001)$ given in table 2.

\section{DISCUSSION}

This survey was conducted to know the recent preferences of core build-up and crown material for ETT in teaching institutes of Multan. According to the results of this survey-based investigation, the majority of the participants preferred amalgam as core build-up material on the basis of strength. Amalgam as a core build-up material was also popular in the United Kingdom. ${ }^{15}$ This may be due to amalgam isn't considered as health hazard in many part of the world and is cost effective.

There was significant association between the build-up time of restoration and workplace of practioners $(p=0.002)$. Majority of the participants working in public place preferred restoration of ETT one week after obturation followed by after one day and immediate, in a sequence. The reason behind this might be the clinical and radiographic evaluation of ETT after one week as observed in a previous study. ${ }^{17}$ The participants working in private place preferred immediate final restoration of ETT over one day and one week. The reason behind this might be to save the time and to avoid coronal leakage leading to failure of endodontic treatment which may occur in immediate temporary restoration, supported by previous studies. ${ }^{18,19}$

According to the results, the majority of the participant $(62 \%)$ had chosen endopost in ETT and prefabricated post were preferred over custom made post, which relates with the observations of other similar studies. ${ }^{20,21}$ The association between endopost type and post-graduation was significant $(p=0.003), 67 \%$ of those who had done post-graduation preferred prefabricated post over custom made post. This trend might be due to fact that prefabricated post are easy to use and can be completed in single visit, so its time saving procedure. Most of the participants believed that core buildup material with endopost should be used as it decreases the chance of tooth fracture. This finding was in accord with dental practitioners practicing in Sweden, Germany and the United States . ${ }^{10,22-24}$

Regarding the crowning of ETT having core build-up, $85.6 \%$ of participants opted such tooth should be crowned. This may be due to the fact that ETT are more prone to fracture than vital teeth and crowning increases their strength and prognosis. Findings of present study are in agreement 
with previous studies. ${ }^{15,25,26}$ The choice of PFM crown increased significantly with the increase in experience $(p=0.001)$. The highest preference of PFM was by those who had experience more than ten years $(76 \%)$. The preference of PFM might be due to the fact that it has better strength to withstand the multidirectional chewing forces especially in molars and it has long term survival. ${ }^{27}$ PFM crowns have good mechanical properties, adequate esthetic results, and an acceptable biological status needed for periodontal health. ${ }^{27}$

This study revealed that amalgam was preferred as core build-up material on the basis of strength. Endo-post was preferred for ETT in order to avoid fracture ${ }^{28}$ and majority of the participants preferred PFM as crown material in ETT. Furthermore, it was observed that PFM was more popular among dentist in teaching institutes of Multan, irrespective of their post-graduation qualification and work place.

\section{CONCLUSION}

Within the limitation of this study, the following conclusion can be drawn;

1. Amalgam was selected as core buildup on the basis of strength.

2. Most of the participants in the present study opted restoration of ETT after one week.

3. Endo-post was preferred by majority of the survey dentist. However, prefabricated post was preferred over custom made on the basis of ease of use and completion in single visit.

4. For crowning of ETT, majority of practitioners irrespective of their clinical experience and post-graduation qualification believed that ETT should be crowned for better prognosis, and PFM was the material of choice for the purpose.

\section{CONFLICT OF INTEREST}

None declared

\section{REFERENCES}

1. Maroulakos G, Nagy WW, Kontogiorgos ED. Fracture resistance of compromised endodontically treated teeth restored with bonded post and cores: An in vitro study. J Prosthet Dent. 2015;114:390-97. https://doi.org/10.1016/j.prosdent.2015.03.017

2. Khurshid Z, Zafar M, Qasim S, Shahab S, Naseem M, AbuReqaiba A. Advances in nanotechnology for restorative dentistry. Dent Mater J. 2015;8:717-31.

https://doi.org/10.3390/ma8020717
3. Samran A, El Bahra S, Kern M. The influence of substance loss and ferrule height on the fracture resistance of endodontically treated premolars. An in vitro study. Dent Mater J. 2013;29:1280-6.

https://doi.org/10.1016/j.dental.2013.10.003

4. Abduljawad M, Samran A, Kadour J, Al-Afandi M, Ghazal M, Kern M. Effect of fiber posts on the fracture resistance of endodontically treated anterior teeth with cervical cavities: An in vitro study. J Prosthet Dent. 2016;116:80-4.

https://doi.org/10.1016/j.prosdent.2015.12.011

5. Habib SR, Al Rifaiy MQ, Alkunain J, Alhasan M, Albahrani J. Concepts of restoring endodontically treated teeth among dentists in Saudi Arabia. Saudi J Dent Res. 2014;5:15-20.

https://doi.org/10.1016/j.ksujds.2013.08.004

6. Chugal NM, Clive JM, Spångberg LS. Endodontic treatment outcome: effect of the permanent restoration. Oral Surg Oral Med Oral Pathol Oral Radiol Endod. 2007;104:576-82.

https://doi.org/10.1016/j.tripleo.2007.04.011

7. Safavi KE, Dowden WE, Langeland K. Influence of delayed coronal permanent restoration on endodontic prognosis. Dent Traumatol. 1987;3:187-91.

https://doi.org/10.1111/j.1600-9657.1987.tb00622.x

8. Lynch C, Burke F, Ní RR, Hannigan A. The influence of coronal restoration type on the survival of endodontically treated teeth. EJPRD - Eur. J. Dent.. 2004;12:171-6.

9. Bonilla ED, Mardirossian G, Caputo A. Fracture toughness of various core build-up materials. J Prosthodont. 2000;9:14-8.

https://doi.org/10.1111/j.1532-849X.2000.00014.x

10. Naumann M, Kiessling S, Seemann R. Treatment concepts for restoration of endodontically treated teeth: A nationwide survey of dentists in Germany. J Prosthet Dent. 2006;96:332-38.

https://doi.org/10.1016/j.prosdent.2006.08.028

11. Mangold JT, Kern M. Influence of glass-fiber posts on the fracture resistance and failure pattern of endodontically treated premolars with varying substance loss: an in vitro study. J Prosthet Dent. 2011;105:38793.

https://doi.org/10.1016/S0022-3913(11)60080-2

12. Cheung W. A review of the management of endodontically treated teeth: Post, core and the final restoration. J Am Dent Assoc. 2005;136:611-19.

https://doi.org/10.14219/jada.archive.2005.0232

13. Sorensen JA, Martinoff JT. Endodontically treated teeth as abutments. J Prosthet Dent. 1985;53:631-36.

https://doi.org/10.1016/0022-3913(85)90008-3

14. Nagasiri R, Chitmongkolsuk S. Long-term survival of endodontically treated molars without crown coverage: a retrospective cohort study. J Prosthet Dent. 2005;93:164-70.

https://doi.org/10.1016/j.prosdent.2004.11.001

15. Aquilino SA, Caplan DJ. Relationship between crown placement 
and the survival of endodontically treated teeth. J Prosthet Dent. 2002;87:256-63.

https://doi.org/10.1067/mpr.2002.122014

16. Hussey D, Killough S. A survey of general dental practitioners' approach to the restoration of root-filled teeth. Int Endod J. 1995;28:914.

https://doi.org/10.1111/j.1365-2591.1995.tb00165.x

17. Trope M, Delano EO, Ørstavik D. Endodontic treatment of teeth with apical periodontitis: single vs. multivisit treatment. J Endod. 1999;25:345-50.

https://doi.org/10.1016/S0099-2399(06)81169-6

18. Ratnakar P, Bhosgi R, Metta KK, Aggarwal K, Vinuta S, Singh N. Survey on restoration of endodontically treated anterior teeth: a questionnaire based study. J Int Oral Health. 2014;6:41.

19. Saunders W, Saunders E. Coronal leakage as a cause of failure in root-canal therapy: a review. Dent Traumatol. 1994;10:105-08. https://doi.org/10.1111/j.1600-9657.1994.tb00533.x

20. Naumann M, Neuhaus KW, Kölpin M, Seemann R. Why, when, and how general practitioners restore endodontically treated teeth: a representative survey in Germany. Clin Oral Investig. 2016;20:25359.

https://doi.org/10.1007/s00784-015-1505-5

21. Rabi T, Rabi T. Attitudes of Palestinian Dentists toward Restoration of Endodontically Treated Teeth. Int J Prosthodont Restor Dent. 2015;5:44-50.

https://doi.org/10.5005/jp-journals-10019-1128

22. Morgano SM, Hashem AF, Fotoohi K, Rose L. A nationwide survey of contemporary philosophies and techniques of restoring endodontically treated teeth. J Prosthet Dent. 1994;72:259-67. https://doi.org/10.1016/0022-3913(94)90339-5

23. Eckerbom M, Magnusson T. Restoring endodontically treated teeth: a survey of current opinions among board-certified prosthodontists and general dental practitioners in Sweden. Int J Prosthodont. 2001;14245-249.

24. Sambrook R, Burrow M. A survey of Australian prosthodontists: the use of posts in endodontically treated teeth. ANZ J Surg. 2018;63:294-301

https://doi.org/10.1111/adj.12620

25. Pratt I, Aminoshariae A, Montagnese TA, Williams KA, Khalighinejad N, Mickel A. Eight-year retrospective study of the critical time lapse between root canal completion and crown placement: its influence on the survival of endodontically treated teeth. J Endod. 2016;42:1598-603.

https://doi.org/10.1016/j.joen.2016.08.006

26. Yee K, Bhagavatula P, Stover S, Eichmiller F, Hashimoto L, MacDonald S, et al. Survival Rates of Teeth with Primary Endodontic Treatment after Core/Post and Crown Placement. J Endod. 2018;44:22025.

https://doi.org/10.1016/j.joen.2017.08.034

27. Ozer F, Mante FK, Chiche G, Saleh N, Takeichi T, Blatz MB. A retrospective survey on long-term survival of posterior zirconia and porcelain-fused-to-metal crowns in private practice. Quintessence Int. 2014;45:31-8.

28. Saritha MK, Paul U, Keswani K, Jhamb A, Mhatre SH, Sahoo PK. Comparative evaluation of fracture resistance of different post systems. J Int Soc Prev Community Dent.2017;7:356.

https://doi.org/10.4103/jispcd.JISPCD_413_17 